\title{
Potential Role of Glucocorticoid Signaling in the Formation of Pancreatic Islets in the Human Fetus
}

\author{
FRANZISKA PHAN-HUG, FABIEN GUIMIOT, VINCENT LELIÈVRE, ANNE-LISE DELEZOIDE, PAUL CZERNICHOW, \\ BERNADETTE BREANT, AND BERTRAND BLONDEAU
}

\begin{abstract}
INSERM [F.P.-H., B.B., B.B.], Fetopathology Department [F.G., A.-L.D.], Endocrinology-Diabetology Department [P.C.], Université Denis Diderot-Paris 7, 75019 Paris, France; INSERM [B.B., B.B.], Centre de Recherche des Cordeliers [B.B., B.B.], Université Pierre et Marie Curie-Paris 6, 75006 Paris, France; UMR S872 [B.B., B.B.] Université Paris Descartes, 75006 Paris, France; INCI [V.L.], UMR7168/LC2, CNRS-Université Louis Pasteur, 67084 Strasbourg Cedex, France
\end{abstract}

\begin{abstract}
Glucocorticoids have been suggested to play a role in programming late adult disorders like diabetes during fetal life. Recent work in rodents showed their role in pancreas development by modulating the expression of transcription factors. The aim of this work was to investigate their possible implication in human pancreas development. The ontogenesis of glucocorticoid receptor (GR) and several pancreatic transcription factors was studied by immunohistochemistry and RT-PCR on human fetal pancreatic specimens. At 6 wk of development (wd) insulin promoting factor 1 (IPF1) was expressed in the majority of epithelial cells forming tubular structures while GR was present in the mesenchyme, suggesting an early role of glucocorticoids, before endocrine and exocrine differentiation. Only GR $\alpha$ (active form) mRNA was expressed from $6 \mathrm{wk}$ onwards while GR $\beta$ (inactive form) was never observed. The first insulin cells did not express IPF1 or GR. Islet formation occurred from $10 \mathrm{wd}$ as IPF1-positive cells started to express simultaneously insulin and GR. This coexpression in $\beta$ cells persisted until adulthood. The mRNA expression profiles confirmed immunohistochemistry and showed the early expression of crucial transcription factors. In conclusion, the presence of the active GR isoform around islet formation supports the novel idea that glucocorticoids could modulate human pancreas development. (Pediatr Res 64: 346-351, 2008)
\end{abstract}

$\mathbf{I}_{\mathrm{n}}^{\mathrm{n}}$ nadequate functional pancreatic $\beta$ cell mass is now recognized as a crucial component in the pathophysiology of type 2 diabetes. Cell lineage tracing and the generation of genetically modified mice have shown the requirement of a large number of transcription factors controlling the development of the endocrine pancreas $(1,2)$ even though their chronology of action is not fully understood yet. The transcription factors Pdx-1/IPF1 (insulin promoting factor 1) and P48/PTF1A (pancreas transcription factor $1 \mathrm{~A}$ ) play determinant roles on pancreas development in mice and are expressed early in pancreatic precursor cells. Later, Pdx-1/IPF1 is mostly restricted to mature $\beta$ cells and $\mathrm{P} 48 / \mathrm{PTF} 1 \mathrm{~A}$ is a prerequisite to drive exocrine cell differentiation. The inactivation of $P d x-1 / I P F 1$ or $P 48 / P T F 1 A$ leads to pancreatic agenesis in mice (3-5) and in humans, mutations in IPFI or PTFIA are also associated

Received February 28, 2008; accepted April 30, 2008.

Correspondence: Bernadette Breant, Ph.D., UMR S872, Centre de Recherche des Cordeliers, Université Pierre et Marie Curie Paris 6, 15 rue de l'Ecole de Medecine, 75006 Paris, France; e-mail: bernadette.breant@crc.jussieu.fr

Supported by the grants from the Institut National de la Santé et de La Recherche Médicale (INSERM) and the European contract NUTRIX QLK1-2,000-00,083. FPH was supported by the Swiss National Science Foundation Grant Nr. PBZHB-102415. with pancreatic agenesis $(6-8)$, MODY or type 2 diabetes $(9-11)$ or neonatal diabetes mellitus (12). Studies on human pancreas development are scarce and little is known about the early expression of these markers in the human fetal pancreas.

There is growing evidence that glucocorticoid (GC) signaling may play a major role in pancreas development and thereby be involved in abnormalities of glucose homeostasis later in life. Hence, prenatal GC exposure has been proposed as one mechanism to explain the link between intra-uterine growth retardation and the increased risk of glucose intolerance, type 2 diabetes and other cardiovascular risks in adults (13-16). In humans, Reinisch et al. (17) have described that prednisone treatment for infertility and subsequent pregnancy maintenance results in a significant decrease in the birth weight of full-term babies. In rodents, fetal overexposure to GC either by maternal dexamethasone treatment, low protein diet or food restriction leads to low birth weight, decrease in $\beta$ cell mass and later impairment of glucose tolerance and/or hypertension (18-20). In this situation Pdx-1/IPF1 mRNA levels were decreased $(21,22)$ and P48/PTF1A mRNA levels increased (21). Additionally, inactivation of the glucocorticoid receptor gene in pancreatic precursor cells suppressing all GC effects in the pancreas is associated with increased $\beta$-cell mass (21).

The key role of GC on pancreas development in rodents by the modulation of specific transcription factors as well as the known effect of GC to favor organ maturation (23) prompted us to study if these hormones could play a role in human pancreas development. This question is of clinical importance in the context of antenatal GC therapy used for prenatal lung maturation or treatment of prenatal congenital adrenal hyperplasia $(24,25)$.

We hypothesized that GC would be acting on pancreas development at a particular time window when glucocorticoid receptor (GR) is highly expressed, a period likely to be more sensitive to excess GC. In humans, GC bind to the active GR $\alpha$ isoform on target cells by triggering phosphorylation, dimerization, and translocation of GR into the nucleus. The GR $\alpha$

Abbreviations: GC, glucocorticoids; GR, glucocorticoid receptor; IPF1, insulin promoting factor (human) equivalent to Pdx-1 (mouse); P48/PTF1A, pancreas transcription factor 1A; PTF1A, pancreas transcription factor (human) equivalent to P48 (mouse) 
binds to specific response elements of DNA thereby enhancing or repressing the transcription of genes responsible for the hormonal effect (26). A second isoform, GR $\beta$, truncated in the C-terminal hormone-binding domain is unable to bind the hormone (27).

The present work characterizes in the developing human pancreas the GC-sensitive cells expressing GR together with those expressing the transcription factors IPF1 and PTF1A and/or the pancreatic hormones, using immunohistochemistry on human pancreatic sections from very early (6 wk) to late (23 wk) stages of development. The mRNA expression profiles of the GR isoforms and various pancreatic transcription factors and hormones were studied by RT-PCR at the same developmental stages.

\section{MATERIALS AND METHODS}

Tissues. The collection and use of human embryonic and fetal material were carried out following the French bioethical law and recommendation, informed consent were obtained and the study was approved by the Institut National de la Santé et de la Recherche Médicale (INSERM). Early embryological stage human embryos were collected following voluntary surgical termination of pregnancy by aspiration. Second trimester pancreata were obtained following infant death in utero after sudden medical problem of the mother. Known fetal pathologies, such as chromosomal aberrations, malformations, or genetic disease that could alter pancreas morphology were excluded. Estimation of fetal age (as weeks postconception or weeks of development) was given by echographic occipito-parietal measurements and hand and foot length measurement by the fetopathologist.

Immunohistochemical studies. Human fetal pancreatic specimen were promptly fixed in $4 \%$ formaldehyde, embedded in paraffin, and sectioned at 5 $\mu \mathrm{m}$ thickness. After analysis on hematoxylin and eosin-stained sections, 14 pancreatic specimens showed sufficient tissue quality to be included in this study. Antigen retrieval was performed by microwave treatment in citrate solution (Biogenex). Nonspecific sites were blocked in $1 \times$ Tris Buffered Saline (TBS) containing $0.1 \% /$ Tween and 3\%BSA after a pretreatment with $0.3 \%$ Triton before overnight incubation at $4^{\circ} \mathrm{C}$ with primary antibodies. They were: rabbit anti-IPF1 (kind gift from R. Scharfmann), rabbit anti-human GR polyclonal antibody (ABR, PA1-511, hGR 346-367), rabbit anti-human GR $\alpha$ (PA1-516, ABR hGR $\alpha$ 755-771), mouse anti-insulin (Sigma Chemical Co., St. Louis, MO), mouse anti-glucagon (Sigma Chemical Co. St. Louis, MO). The rabbit antiserum against PTF1A was raised by us against a synthetic amino acid peptide (C-KSFDNIENEPPFEFVS) corresponding to the carboxyl-terminal 16 amino acids of mouse and rat PTF1A. Secondary antibodies were biotin-conjugated anti-rabbit (Jackson Immuno Research Laboratories, West Grove, PA) and peroxidase-conjugated anti-mouse (Amersham Biosciences). DAB (3,3-diaminobenzidine tetrahydrochloride, Dako) and Fast Red (Dako) were used as substrates for peroxidase and alkaline phosphatase, respectively.

The specificity of the anti-GR antibody was assessed by clearing the signal upon incubation with the synthetic peptide, the absence of signal in GR ${ }^{\text {null/null }}$ mouse embryonic pancreas tissues and a positive signal in $\mathrm{GR}^{+/+}$mouse pancreas (data not shown).

RNA extraction and cDNA synthesis. Quickly dissected human fetal pancreatic specimens were frozen in liquid nitrogen and stored at $-80^{\circ} \mathrm{C}$. RNA was prepared with the RNeasy minikit (Qiagen) with on-column DNase treatment. Total RNA was reverse transcribed into cDNA using oligo(dT) and SuperScript II RNase H reverse transcriptase (In Vitrogen) following manufac- turer's instruction. The contamination of pancreatic tissues by duodenum, liver, or spleen was excluded by the absence of Sonic Hedgehog amplification, which was detected in liver and lung.

$\boldsymbol{R T}$-PCR. M-fold software (http://www.bioinfo.rpi.edu/applications/mfold/ old/dna/form1.ogi) allowed the analysis of the secondary structures of published sequence of cDNA encoding for human GR $\alpha, \mathrm{GR} \beta$, IPF1, insulin, and NEUROG3. The fragments of sequences lacking any stable secondary structure at $58^{\circ} \mathrm{C}$ were imported into Oligo6 software (Molecular Biology Insights, Cascade, $\mathrm{CO}$ ) to design highly stringent primer sets (Table 1). The primers were blasted in cDNA database to ensure their specificity. The nature of the amplified DNA for GR $\alpha$ and GR $\beta$ primer products was ultimately confirmed by sequencing. Human glyceraldehyde-3-phosphate dehydrogenase $(\mathrm{GAPDH})$ was used as an internal control. Primers were intron spanning with the exception of IPFI.

cDNAs were amplified using SYBR® Greensupermix from Bio-Rad (Hercules, CA) and $300 \mathrm{nM}$ of each specific primer for 45 cycles. Amplification specificity was visualized by melting curve analyses. Each sample was assessed in duplicate. Expression levels were calculated as the ratio between the gene of interest and GAPDH (internal control).

\section{RESULTS}

Development of pancreatic structures in the human fetus. At $6 \mathrm{wd}$, the human pancreatic epithelium was composed of tubular structures surrounded by a dense mesenchyme next to the duodenal structure. At this stage, the transcription factor IPF1 was present in duodenal structures and the majority of pancreatic epithelial cell nuclei (Fig. 1, 6 wd). At $9 \mathrm{wd}$, epithelial cell tubules were branched, few isolated insulin cells were observed within the epithelium, and small insulin cell clusters start to form (Fig. 1, 9 wd). The mesenchymal tissue was abundant. The number of IPF1 positive cells increased with further branching between 9 and 13 wd (Fig. 1). At 13 wd, insulin cell clusters were larger and next to the epithelial structures. At this stage, trefoiled epithelial cell clusters not belonging to islets but also expressing IPF1 became visible at distance of the duct-like structures (Figs. 1 and $4 C-D)$. At 22-23 wd, mesenchymal tissue had decreased while epithelial cell clusters were well distinguished from islet cells. First typical acinar structures were recognized. At that stage and adulthood, IPF1 was exclusively expressed in $\beta$ cells containing insulin and few ductal cells (Fig. 2) and not detected anymore in the exocrine tissue when acinar formation was completed. At adulthood, mesenchymal tissue had mostly disappeared and the islets were surrounded by abundant acinar structures and ductal cells (Fig. 2). As expected for a transcription factor, the IPF1 signal in our study was nuclear at all stages examined, in contrast to nuclear and cytoplasmatic IPF1 staining observed in another study (28).

Ontogenesis of the GR in the developing human pancreas during islet differentiation. At $6 \mathrm{wd}$, the first GR-positive cells were the mesenchymal cells and the first IPF1-positive epithelial cells were GR-negative (Fig. 1). The first insulin

Table 1. Primers used for regular PCR (Sonic Hedgehog) and RT-PCR (all others)

\begin{tabular}{lll}
\hline \multicolumn{1}{c}{ Gene } & \multicolumn{1}{c}{ Forward primer } & \multicolumn{1}{c}{ Reverse primer } \\
\hline Sonic hedgehog & GCCATCTCTGTGATGAACCA & CCACGGAGTTCTCTGCTTTC \\
GR $\alpha$ & CGGTTTTATCAACTGACAA & GGGAATCAATACTCATGGTC \\
GR $\beta$ & TCAACTGACAAAACTCTTGGA & GAGATGTGCTTTCTGGTTTTA \\
IPF1 & CGCGTCCAGCTGCCTTC & CCACGCGTGAGCTTTGGTAGA \\
NEUROG3 & CCCTCGCTGCTCATCGCTCTC & GGCGTCATCCTTTCTACCG \\
Insulin & AGGACAGGCTGCATCAGAA \\
PTF1A & CCCCAGAAAACTCAACAGCA & CATGGCAGAAGGACAGTGATC \\
GAPDH & TCCAGGAGCGAGATCCC & AATCAGATCTTCAGCCGAGTC \\
\hline
\end{tabular}




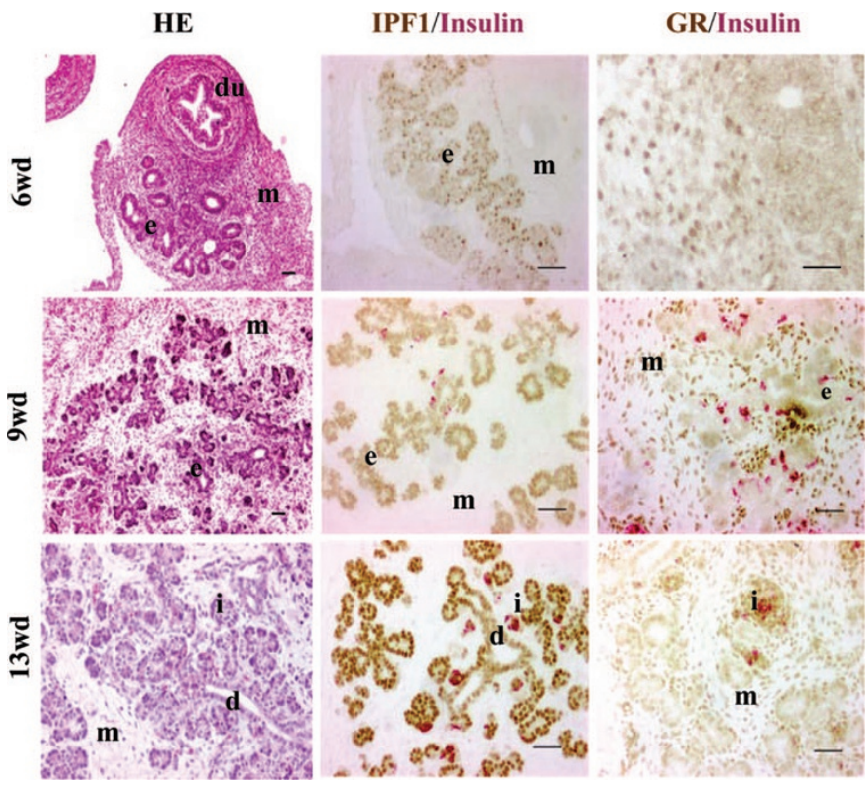

Figure 1. Ontogenesis of IPF1 and GR in the human pancreasTissue organization of normal human pancreas at different stages of development was visualized on paraffin sections by hematoxy-eosin staining (left column, scale bars $50 \mu \mathrm{mm}$ ). Dual immunohistochemistry shows the timing of appearance of IPF1 (brown, middle column) and GR (brown, right column), in relationship with that of insulin in red (middle and right columns); scale bars 25 $\mathrm{m} \mu \mathrm{mm}$, except GR/Insulin at $6 \mathrm{wd}, 20 \mu \mathrm{mm}$. At $6 \mathrm{wk}$ of development Pancreas transcription (wd) IPF1 is detected in all epithelial cells $(e)$ whereas GR is only expressed in mesenchymal cells $(m)$. IPF1 expression increases with branching of the pancreatic epithelium at $9-13$ wd while nuclear GR expression is now observed in clusters of insulin-containing cells. $d$, duct; $d u$, duodenum; $e$, epithelial cell; $m$, mesenchymal cell; $i$, islet.

cells at $9 \mathrm{wd}$, which were isolated and located within the wall of the epithelial tubules (Fig. 3, ii) were GR-and-IPF1negative (Fig. 3). During islet formation, insulin-expressing cells appear as clusters (Fig. 3, ic), which were first attached to the duct-like structures at $10 \mathrm{wd}$ and located at distance of the ducts at $13 \mathrm{wd}$ (Fig. 4). Insulin cells grouped in clusters expressed both GR and IPF1 (Fig. 3, ic). The colocalization of IPF1 and GR in human epithelial cells thus coincided with the onset of islet formation. In formed islets at $22-23 \mathrm{wd}, \beta$ cells continued to express GR and IPF1 and were the only pancreatic cells to do so until adulthood (Fig. 2). Glucagon cells did not show any GR immunostaining at early (Fig. 3) or later stages (not shown). Tracing experiments in mice have shown that PTF1A is necessary for the maintenance of pancreatic progenitors and later for the differentiation of exocrine cells $(3,4)$. In the human fetal pancreas, PTF1A was expressed as early as $8 \mathrm{wd}$ in a large subset of IPF1-positive epithelial cells (Fig. $4 A$ and $B$ ), indicating that PTF1A is also a marker of human pancreatic progenitors. At 12-13 wd, trefoiled IPF1positive-and-insulin-negative epithelial cell clusters located at distance of the islets also expressed PTF1A in their nucleus (Fig. $4 C$ and $D$ ), likely representing the future acinar cell population. A cytoplasmic signal for carboxypeptidase A was observed in these cells (results not shown). At 16 and 22-23 wd, PTF1A positive cells formed more typical acinar structures (Fig. 4) that expressed GR (Fig. 3, 22-23 wd) but mature acini did not (Fig. 3, adult).

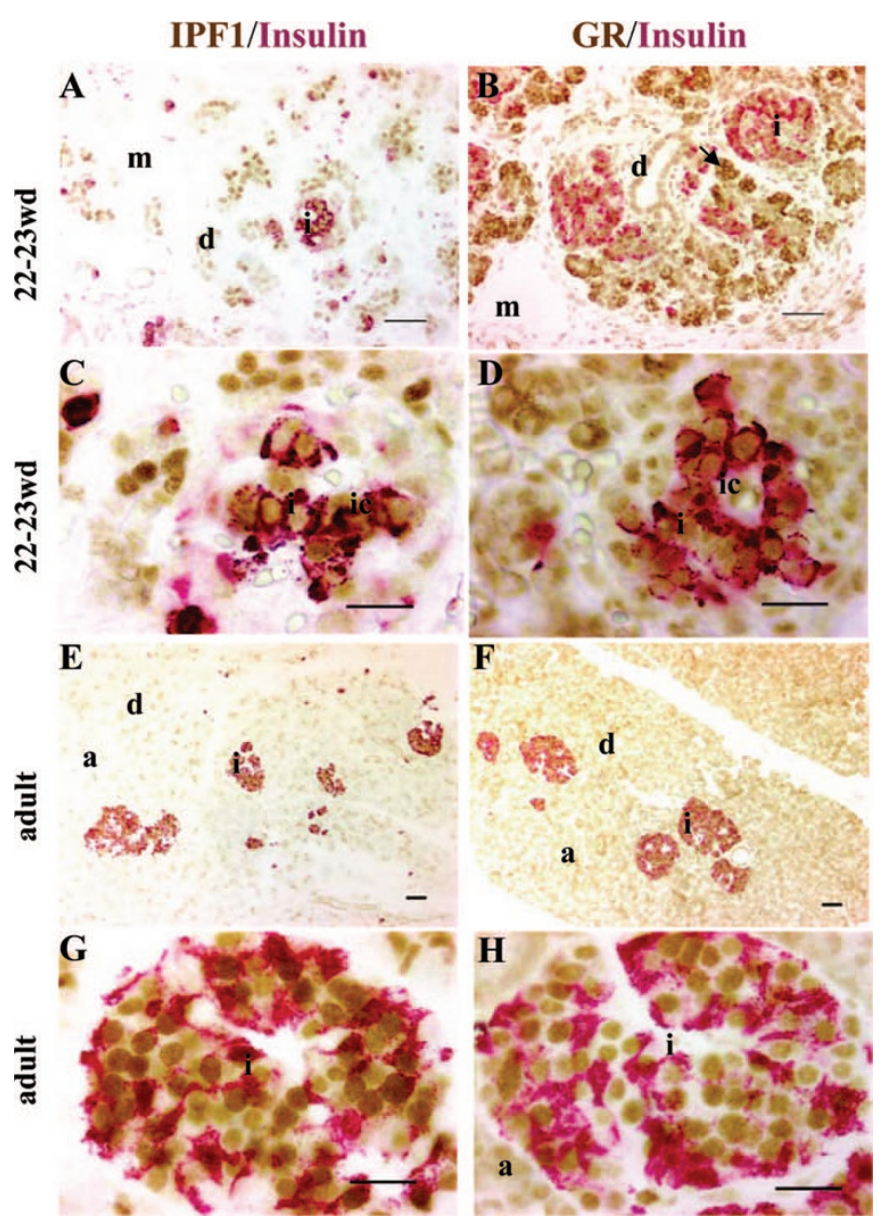

Figure 2. IPF1 and GR expression at later stages. At 22-23 wd, IPF1 and GR are detected in $\beta$ cells and few ductal cells $(A-D)$ and GR is also expressed in forming acini (arrows, $B$ and $D$ ). At adult age, IPF1 and GR are exclusively expressed in $\beta$ cells $(E-H)$. $a$, acini; $d$, duct; $m$, mesenchymal cell; $i$, islet; $i c$,

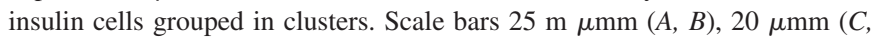
$D, G, H)$ or $50 \mathrm{~m} \mu \mathrm{mm}(E, F)$.

mRNA expression profiles during human pancreas development. The profile of mRNA expression of the active GR $\alpha$ and the inactive (or suppressor) GR $\beta$ forms were analyzed by RT-PCR and compared with that of insulin and pancreatic transcription factor mRNAs (Fig. 5). The active GR $\alpha$ form was found as soon as $6 \mathrm{wd}$ with a higher expression around $8-9$ wd. The GR $\beta$ was never detected at any developmental stage examined $(\mathrm{GR} \beta / \mathrm{GAPDH}$ ratio $<0.00001)$. Insulin mRNA was weakly expressed until 9 wd (insulin/GAPDH ratio $=0.018)$ with a 12-fold increase between 8-9 and $10-11$ wd (insulin/ GAPDH ratio $=0.23$ ) and a further 10-fold increase between 10-11 and $22 \mathrm{wd}$ (insulin/ GAPDH ratio $=2.06)$. IPF1 mRNA was detected at all stages examined with minimal variations, consistent with the expression of this factor in pancreatic cells at various stages of differentiation, including differentiated $\beta$ cells. NEUROG3 mRNA was observed throughout pancreas development, consistent with the continuous endocrine cell differentiation in the pancreas during fetal life in human (29-31). PTF1A mRNA was detectable at all stages with low levels until $10 \mathrm{wd}$ and maximal expression levels at late stages, underlying its importance in early pancreatic progenitors and consistent with its implication in exocrine cell differentiation. 


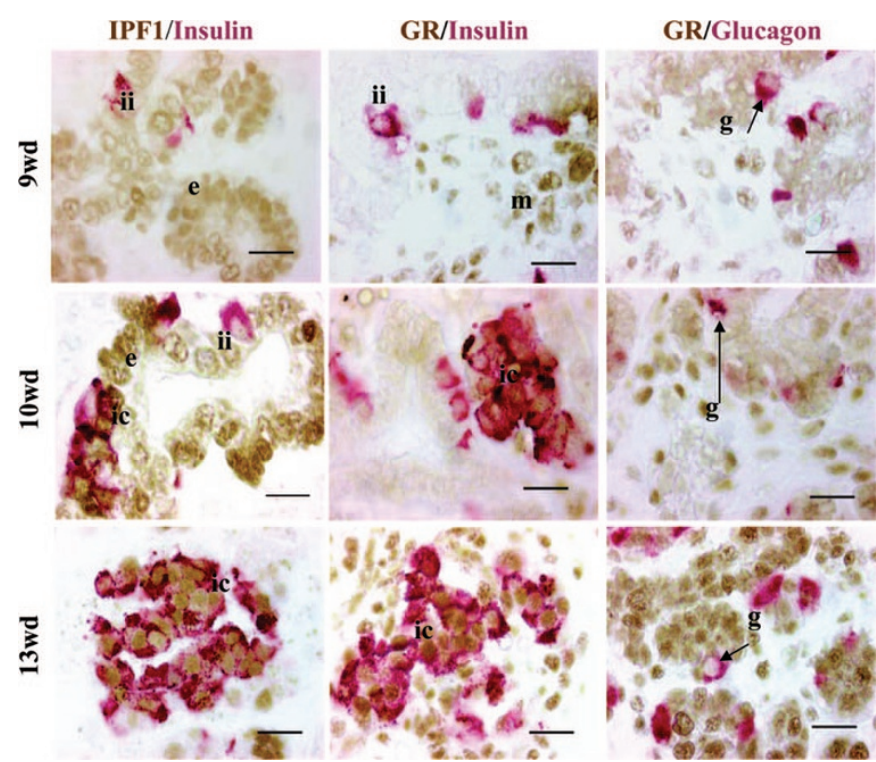

Figure 3. Expression of IPF1 and GR during human islet formation. At 9 and $10 \mathrm{wd}$, IPF1 (brown, left column) is expressed in epithelial cells but not in isolated insulin cells (red, ii). From $10 \mathrm{wd}$, IPF1 is expressed in insulin cells grouped into clusters (ic) and so does GR (brown, middle column). Note that glucagon cells (red, right column) express neither IPF1 nor GR. $g$, glucagon cell; $e$, epithelial cell; $m$, mesenchymal cell; $i$, islet; $i i$, isolated insulin cell; $i c$, insulin cells grouped in clusters. Scale bars $20 \mu \mathrm{mm}$.
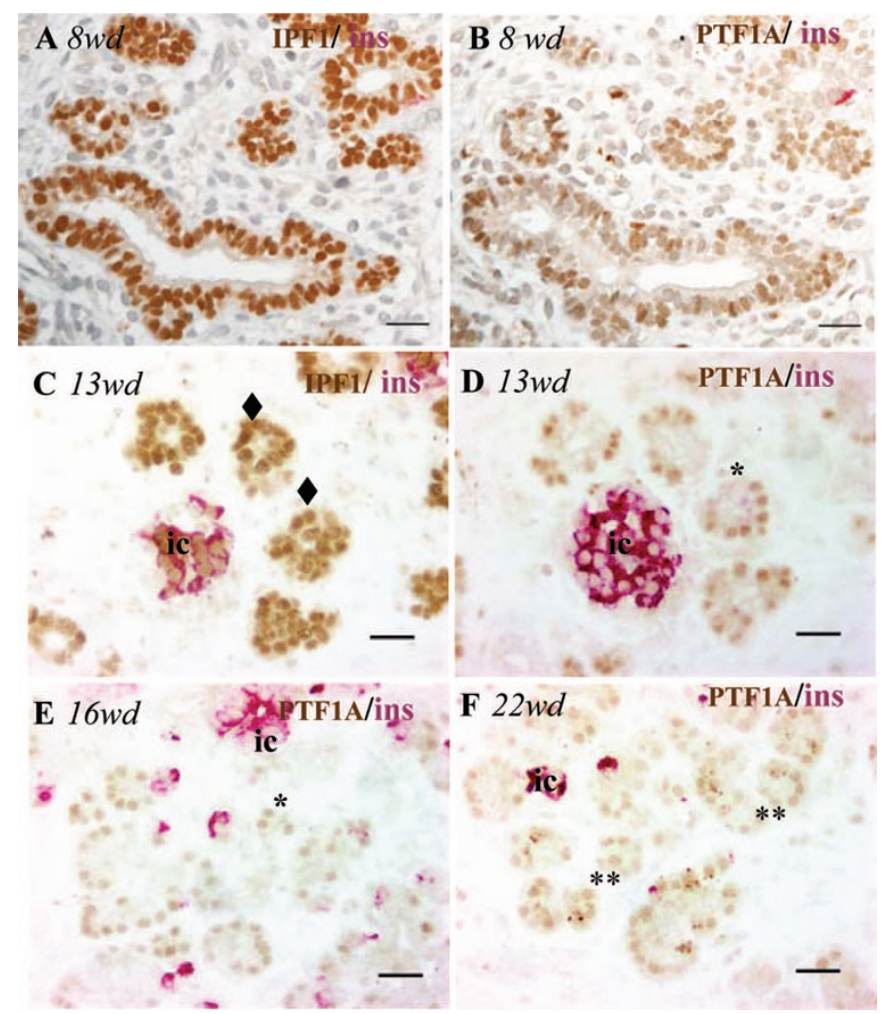

Figure 4. Exocrine pancreas development. At $8 \mathrm{wd}$, PTF1A (brown, B) is expressed in a large subset of IPF1-positive epithelial progenitor cells (brown, A). At $13 \mathrm{wd}$, IPF1 (brown, $C$ ) is expressed in insulin cells forming islets (red, $i c$ ), as well as in trefoiled (see Fig. 1) or tubule-like epithelial cells (diamonds) also expressing the exocrine transcription factor PTF1A (D, asterisks), likely representing the future acini. $A-B$ and $C-D$ are consecutive sections, respectively. PTF1A-positive structures shown by asterisks are also observed at 16 wd $(E)$ and $22 \mathrm{wd}(F)$. Scale bars $25 \mu \mathrm{m}$.

\section{DISCUSSION}

Our results show the presence of the active form of the glucocorticoid receptor (GR) in the human developing pancreas as soon as $6 \mathrm{wd}$ in the mesenchymal cells but not in the first immature endocrine cells dispersed in the epithelial tubules. As differentiation progresses, the GR is observed in a subfraction of IPF1-positive epithelial cells at the time they express insulin and organize into islet-like clusters. These findings further document how human pancreas develops and support the novel idea that glucocorticoids (GC) could possibly modulate this development.

The human pancreas develops as ventral and dorsal outgrowths of the foregut endoderm, initiating at about 3-4 wd with the dorsal derivative. The fusion of the ventral and dorsal bud takes place at $8 \mathrm{wd}(28)$. At $6 \mathrm{wd}$, IPF1 was present in the majority of epithelial cell nuclei from the tubular structures budding from the duodenum into a dense mesenchyme. IPF1 therefore represents an early marker of the human pancreatic epithelium. At this stage, the active form of the GR is present in the mesenchymal cells. As epithelio-mesenchymal interaction is important for pancreas morphogenesis in rodents $(32,33)$, the presence of GR in mesenchymal cells suggests such a role for glucocorticoids during human pancreas development before endocrine and exocrine differentiation take place.

GR and human $\beta$-Cell development. At $9 \mathrm{wd}$, insulin cells and glucagon cells were dispersed in the epithelial cell tubules, in agreement with other observations of the first endocrine cells around 7-8 wd in the human pancreas (29-31). These first insulin cells do not express IPF1 or GR, suggesting that their development is not directly GR-dependent and not IPF1-dependent, as shown in mice (34). This study shows that islet formation starts from $10 \mathrm{wd}$ onwards with insulin cell clusters forming within the epithelial cell tubules. Interestingly, the isolated insulin expressing cells still observed at 10 wd express neither GR nor IPF1 while insulin cells grouped in clusters express both markers. The first period when IPF1positive epithelial cells start expressing insulin thus coincides with endocrine cell clustering. The presence of the GR at this moment in the same epithelial structures points out the potential role of GC on the endocrine differentiation of IPF1positive cells, possibly by modulating IPF1 expression, as already shown in rodents in vivo and in vitro (21). Interestingly, prenatal dexamethasone treatment of pregnant monkeys resulted in reduced $\beta$-cell number in the offspring, highlighting the negative role of GC on $\beta$-cell development also in nonhuman primates (35). From the period of islet formation until adult age, GR and IPF1 colocalize in insulin expressing cells. The fact that mature human $\beta$ cells express a persistent GR signal suggests a possible role of GC on $\beta$ cell function, consistent with the direct inhibition of GC on insulin secretion demonstrated in vivo in humans (36), as well as in vitro and in vivo (37) in mice.

GR and exocrine pancreas development. The development of the exocrine pancreas started 2-3 wk later than that of the endocrine and was observed between 13 and $23 \mathrm{wd}$, characterized at early stages by the nuclear expression of the PTF1A 

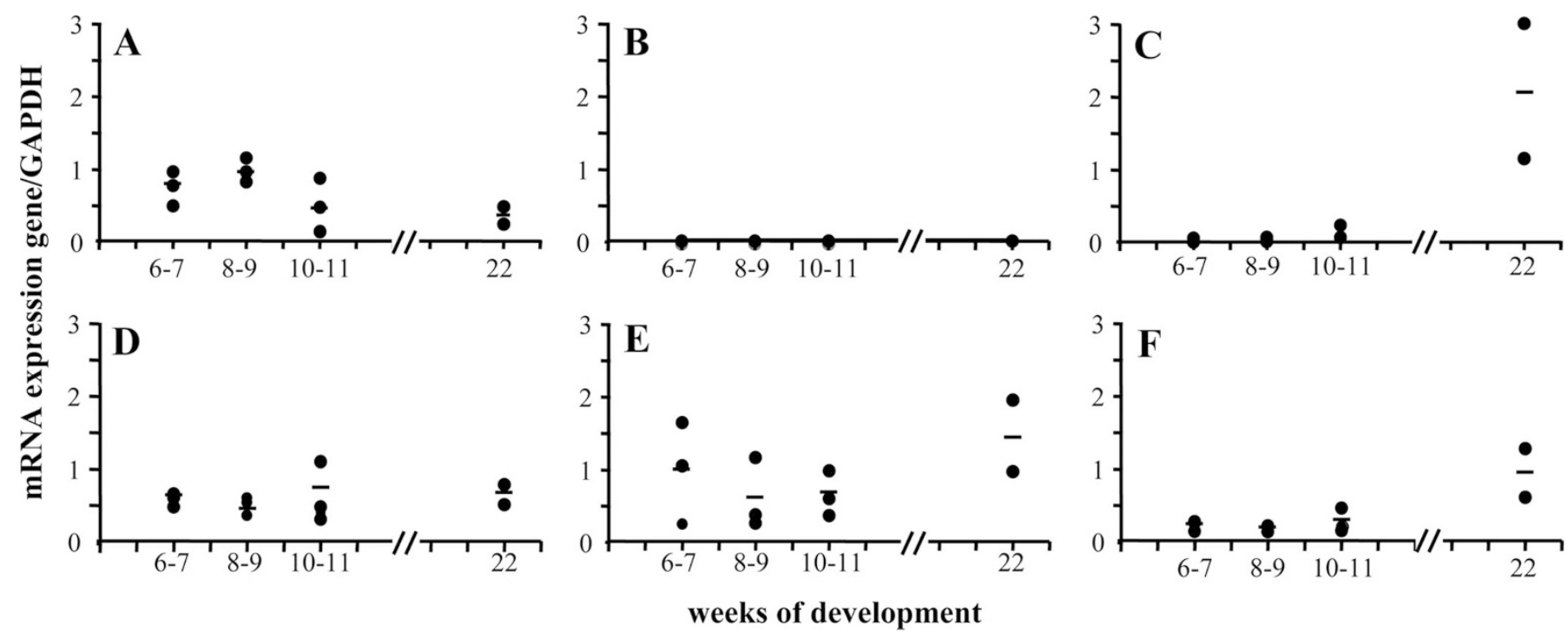

Figure 5. Quantitative expression of GR and transcription factor mRNA during human fetal pancreas development. Three pancreata were analyzed at 6-7 wd, 8-9 wd or 10-11 wd and two at 22 wd for mRNA levels of $(A) \mathrm{GR} \alpha,(B)$ GR $\beta,(C)$ Insulin, $(D)$ Pdx-1, $(E)$ NEUROG3 and $(F)$ PTF1A-. Results are obtained by RT-PCR and expressed as relative ratio to GAPDH mRNA value. The mean ratio value of duplicates for each specimen at each time-point is shown as a single dot.

transcription factor and later by the expression of carboxypeptidase A (not shown). In mature human acinar cells, GR immunoreactivity was never observed, contrasting with its persistent expression in rodent adult acinar cells (21). The presence of GR may no longer be necessary once acinar differentiation is resumed, suggesting that GC would be more likely implicated in the exocrine differentiation process rather than in acinar cell expansion.

The active form of the GR is expressed in the developing human pancreas. The actions of GC are mediated by the GR, which binds GC hormones and regulates gene expression, cell signaling, and homeostasis (38). In recent years, increasing numbers of human GR isoforms generated from one gene have been reported. The GR $\alpha$ form binds the hormone and induces the expression of a $\mathrm{GC}$ responsive reporter gene in a hormone-dependent manner. The GR $\beta$ isoform acts as a dominant negative inhibitor for GR $\alpha$ transcriptional regulation $(39,40)$. Increased GR $\beta$ expression has been correlated with several diseases related to glucocorticoid resistance and inflammatory conditions but is minimally expressed in physiologic conditions $(41,42)$. In line with these observations, the GR $\beta$ isoform mRNA was never detected in the developing human pancreas between 6 and $23 \mathrm{wd}$ and the GR $\alpha$ was the only human GR isoform detected. The profile of the active GR $\alpha$ expression by RT-PCR could define a GC-vulnerable period corresponding to the beginning of islet formation. These results closely match our immunohistochemical observations and are consistent with those obtained after in situ hybridization in mice showing a peak expression of the GR around E14.5-16.5, just before the second wave of $\beta$-cell differentiation (43). Alternatively, it cannot be excluded that the apparent decrease of GR $\alpha$ mRNA observed at late stages reflects variations in nonendocrine cell numbers, such as the continuous expansion of the acinar cells not expressing the GR and the progressive decrease of mesenchymal cells initially expressing the GR. The expression profiles of insulin, NEUROG3 and PTF1A were studied in the developing human pancreas. The insulin mRNA profile showing weak levels until 8-9 wd followed by an increase around $11 \mathrm{wd}$ follows our immunohistological findings where insulin cells are present from 8-9 wk and expand thereafter. The proendocrine transcription factor NEUROG3 (2) was already present around 6-7 wd just before islet formation and its expression persists until $22 \mathrm{wk}$, contrasting with the downregulation of this gene at late fetal stages in rodents, but in line with the ongoing islet neogenesis described in the human developing pancreas (29-31). This increase could also suggest that NEUROG3 has functions other than islet differentiation, such as islet innervation. PTF1A mRNA was detectable at all stages examined, consistent with its immunohistological observation as early as $8 \mathrm{wd}$, suggesting that PTF1A is also an early marker of human pancreatic progenitors.

Taken together our results show the presence of the active form of the GR as soon as 6 wd and its colocalization with insulin cells from the beginning of islet formation. These data suggest for the first time a potential regulation of human fetal $\beta$-cell development by GC. Our data show that the mRNA and protein machinery are present in the human fetus for such a regulation to take place. The GC-sensitive period around islet formation points out the potential harmful action of early prenatal GC treatment or stress on human fetal pancreas development with the risk of developing $\beta$-cell insufficiency later in life.

Acknowledgments. We are grateful to R. Scharfmann for the IPF1 antibody. The skillful technical assistance of B. Duchene, MN Lotiquet and B. Bartolt is gratefully acknowledged.

\section{REFERENCES}

\footnotetext{
1. Murtaugh LC 2007 Pancreas and beta-cell development: from the actual to the possible. Development 134:427-438

2. Gradwohl G, Dierich A, LeMeur M, Guillemot F 2000 neurogenin 3 is required for the development of the four endocrine cell lineages of the pancreas. Proc Natl Acad Sci USA 97:1607-1611
} 
3. Krapp A, Knofler M, Ledermann B, Burki K, Berney C, Zoerkler N, Hagenbuchle O, Wellauer PK 1998 The bHLH protein PTF1-P48 is essential for the formation of the exocrine and the correct spatial organization of the endocrine pancreas. Genes Dev 12:3752-3763

4. Kawaguchi Y, Cooper B, Gannon M, Ray M, MacDonald RJ, Wright CV 2002 The role of the transcriptional regulator Ptfla in converting intestinal to pancreatic progenitors. Nat Genet 32:128-134

5. Jonsson J, Carlsson L, Edlund T, Edlund H 1994 Insulin-promoter-factor 1 is required for pancreas development in mice. Nature 371:606-609

6. Stoffers DA, Zinkin NT, Stanojevic V, Clarke WL, Habener JF 1997 Pancreatic agenesis attributable to a single nucleotide deletion in the human IPF1 gene coding sequence. Nat Genet 15:106-110

7. Sellick GS, Barker KT, Stolte-Dijkstra I, Fleischmann C, Coleman RJ, Garrett C, Gloyn AL, Edghill EL, Hattersley AT, Wellauer PK, Goodwin G, Houlston RS 2004 Mutations in PTF1A cause pancreatic and cerebellar agenesis. Nat Genet 36:13011305

8. Schwitzgebel VM, Mamin A, Brun T, Ritz-Laser B, Zaiko M, Maret A, Jornayvaz FR, Theintz GE, Michielin O, Melloul D, Philippe J 2003 Agenesis of human pancreas due to decreased half-life of insulin promoter factor 1. J Clin Endocrinol Metab 88:4398-4406

9. Stoffers DA, Ferrer J, Clarke WL, Habener JF 1997 Early-onset type-II diabetes mellitus (MODY4) linked to IPF1. Nat Genet 17:138-139

10. Macfarlane WM, Frayling TM, Ellard S, Evans JC, Allen LI, Bulman MP, Ayres S, Shepherd M, Clark P, Millward A, Demaine A, Wilkin T, Docherty K, Hattersley AT 1999 Missense mutations in the insulin promoter factor-1 gene predispose to type 2 diabetes. J Clin Invest 104:R33-R39

11. Hani EH, Stoffers DA, Chevre JC, Durand E, Stanojevic V, Dina C, Habener JF, Froguel P 1999 Defective mutations in the insulin promoter factor-1 (IPF-1) gene in late-onset type 2 diabetes mellitus. J Clin Invest 104:R41-R48

12. Sellick GS, Garrett C, Houlston RS 2003 A novel gene for neonatal diabetes maps to chromosome 10p12.1-p13. Diabetes 52:2636-2638

13. Seckl JR 1997 Glucocorticoids, feto-placental 11 beta-hydroxysteroid dehydrogenase type 2, and the early life origins of adult disease. Steroids 62:89-94

14. Doyle LW, Ford GW, Davis NM, Callanan C 2000 Antenatal corticosteroid therapy and blood pressure at 14 years of age in preterm children. Clin Sci (Lond) 98:137-142

15. Dalziel SR, Walker NK, Parag V, Mantell C, Rea HH, Rodgers A, Harding JE 2005 Cardiovascular risk factors after antenatal exposure to betamethasone: 30-year follow-up of a randomised controlled trial. Lancet 365:1856-1862

16. Edwards CR, Benediktsson R, Lindsay RS, Seckl JR 1993 Dysfunction of placental glucocorticoid barrier: link between fetal environment and adult hypertension? Lancet 341:355-357

17. Reinisch JM, Simon NG, Karow WG, Gandelman R 1978 Prenatal exposure to prednisone in humans and animals retards intrauterine growth. Science 202:436438

18. Nyirenda MJ, Lindsay RS, Kenyon CJ, Burchell A, Seckl JR 1998 Glucocorticoid exposure in late gestation permanently programs rat hepatic phosphoenolpyruvate carboxykinase and glucocorticoid receptor expression and causes glucose intolerance in adult offspring. J Clin Invest 101:2174-2181

19. Blondeau B, Lesage J, Czernichow P, Dupouy JP, Breant B 2001 Glucocorticoids impair fetal beta-cell development in rats. Am J Physiol Endocrinol Metab 281:E592-E599

20. Lesage J, Blondeau B, Grino M, Breant B, Dupouy JP 2001 Maternal undernutrition during late gestation induces fetal overexposure to glucocorticoids and intrauterine growth retardation, and disturbs the hypothalamo-pituitary adrenal axis in the newborn rat. Endocrinology 142:1692-1702

21. Gesina E, Tronche F, Herrera P, Duchene B, Tales W, Czernichow P, Breant B 2004 Dissecting the role of glucocorticoids on pancreas development. Diabetes 53:23222329

22. Shen CN, Horb ME, Slack JM, Tosh D 2003 Transdifferentiation of pancreas to liver. Mech Dev 120:107-116
23. Liggins GC 1976 Adrenocortical-related maturational events in the fetus. Am J Obstet Gynecol 126:931-941

24. Spiliotis BE 2001 Prenatal diagnosis and treatment of congenital adrenal hyperplasia and consequences in adults. J Pediatr Endocrinol Metab 14:1299-1302 discussion 1317

25. Crowther CA, Haslam RR, Hiller JE, Doyle LW, Robinson JS 2006 Neonata respiratory distress syndrome after repeat exposure to antenatal corticosteroids: a randomised controlled trial. Lancet 367:1913-1919

26. Kumar R, Thompson EB 1999 The structure of the nuclear hormone receptors Steroids 64:310-319

27. Yudt MR, Cidlowski JA 2001 Molecular identification and characterization of a and $b$ focus of the glucocorticoid receptor. Mol Endocrinol 15:1093-1103

28. Piper K, Brickwood S, Turnpenny LW, Cameron IT, Ball SG, Wilson DI, Hanley NA 2004 Beta cell differentiation during early human pancreas development. J Endocrinol 181:11-23

29. Bouwens L, Lu WG, De Krijger R 1997 Proliferation and differentiation in the human fetal endocrine pancreas. Diabetologia 40:398-404

30. Polak M, Bouchareb-Banaei L, Scharfmann R, Czernichow P 2000 Early pattern of differentiation in the human pancreas. Diabetes 49:225-232

31. Sarkar SA, Kobberup S, Wong R, Lopez AD, Quayum N, Still T, Kutchma A, Jensen JN, Gianani R, Beattie GM, Jensen J, Hayek A, Hutton JC 2008 Global gene expression profiling and histochemical analysis of the developing human fetal pancreas. Diabetologia 51:285-297

32. Scharfmann R 2000 Control of early development of the pancreas in rodents and humans: implications of signals from the mesenchyme. Diabetologia 43:1083-1092

33. Golosow N, Grobstein C 1962 Epitheliomesenchymal interaction in pancreatic morphogenesis. Dev Biol 4:242-255

34. Ahlgren U, Jonsson J, Edlund H 1996 The morphogenesis of the pancreatic mesenchyme is uncoupled from that of the pancreatic epithelium in IPF1/PDX1deficient mice. Development 122:1409-1416

35. de Vries A, Holmes MC, Heijnis A, Seier JV, Heerden J, Louw J, Wolfe-Coote S Meaney MJ, Levitt NS, Seckl JR 2007 Prenatal dexamethasone exposure induces changes in nonhuman primate offspring cardiometabolic and hypothalamic-pituitaryadrenal axis function. J Clin Invest 117:1058-1067

36. Plat L, Byrne MM, Sturis J, Polonsky KS, Mockel J, Fery F, Van Cauter E 1996 Effects of morning cortisol elevation on insulin secretion and glucose regulation in humans. Am J Physiol 270:E36-E42

37. Delaunay F, Khan A, Cintra A, Davani B, Ling ZC, Andersson A, Ostenson CG, Gustafsson J, Efendic S, Okret S 1997 Pancreatic beta cells are important targets for the diabetogenic effects of glucocorticoids. J Clin Invest 100:2094-2098

38. Reichardt HM, Schutz G 1998 Glucocorticoid signalling-multiple variations of a common theme. Mol Cell Endocrinol 146:1-6

39. Bamberger CM, Bamberger AM, de Castro M, Chrousos GP 1995 Glucocorticoid receptor beta, a potential endogenous inhibitor of glucocorticoid action in humans. J Clin Invest 95:2435-2441

40. Yudt MR, Jewell CM, Bienstock RJ, Cidlowski JA 2003 Molecular origins for the dominant negative function of human glucocorticoid receptor beta. Mol Cell Biol 23:4319-4330

41. Webster JC, Oakley RH, Jewell CM, Cidlowski JA 2001 Proinflammatory cytokines regulate human glucocorticoid receptor gene expression and lead to the accumulation of the dominant negative beta isoform: a mechanism for the generation of glucocorticoid resistance. Proc Natl Acad Sci USA 98:6865-6870

42. Pujols L, Mullol J, Roca-Ferrer J, Torrego A, Xaubet A, Cidlowski JA, Picado C 2002 Expression of glucocorticoid receptor alpha- and beta-isoforms in human cells and tissues. Am J Physiol Cell Physiol 283:C1324-C1331

43. Speirs HJ, Seckl JR, Brown RW 2004 Ontogeny of glucocorticoid receptor and 11 beta-hydroxysteroid dehydrogenase type-1 gene expression identifies potentia critical periods of glucocorticoid susceptibility during development. J Endocrinol 181:105-116 